\title{
THE CORRELATION BETWEEN HAZE AND ECONOMIC GROWTH: BIBLIOMETRIC ANALYSIS BASED ON WOS DATABASE
}

\author{
XIONG, $\mathrm{H}^{{ }^{*}}{ }^{*}-\mathrm{ZHAO}, \mathrm{Z}^{2}$ \\ ${ }^{1}$ School of Management, Nanchang University, Nanchang 330031, China \\ ${ }^{2}$ Institute of China's Science, Technology and Education Policy, Zhejiang University, \\ Hangzhou 310058, China \\ *Corresponding author \\ e-mail:xionghuanhuan@ncu.edu.cn
}

(Received $6^{\text {th }}$ May 2019; accepted $15^{\text {th }}$ Nov 2019)

\begin{abstract}
This paper takes 4,225 articles on the relationship between haze and economic growth in the Web of Science database from 1992 to 2017 as the research object, and uses CiteSpace to explore the spatial and temporal distribution, research topics and hot trends of the literature. The results show that: (1) The relevant literature volume keeps growing at a high speed. (2) The cooperative group of high-yield authors represented by Huang GH and Streets DG is basically formed. (3) The research institutions are divided into the top international colleges and universities represented by Tsinghua University and the University of California, Berkeley, as well as the two major groups of international well-known scientific research institutes represented by the Chinese Academy of Sciences and the American Environmental Protection Agency. (4) The cited high literature is concentrated in the six international high level journals such as "Science". (5) The two major cooperation bodies of "the United States-China" and "HollandFrance-Italy-Spain" have been formed. (6) The research topics are mainly about the economic mechanism of haze formation, its relationship with economic growth, spatial spillover effects and countermeasures. (7) The research hotspots show trends from "air pollution" and "health" to " $\mathrm{PM}_{2.5}$ " and " $\mathrm{CO}_{2}$ emission".
\end{abstract}

Keywords: $P M_{2.5}$, EKC, spatial spillover, knowledge map, CiteSpace, hot trend

\section{Introduction}

In recent years, with the continuous expansion of China's population and rapid economic development, energy consumption has been increasing, and air pollution problems such as smog and haze have become increasingly serious. Haze will not only seriously affect people's physical and mental health, but also cause a certain degree of impact on traffic safety, agricultural production, ecological environment and economic development. According to the calculation results of official agencies such as the World Bank and the environmental protection administration, the annual loss due to environmental pollution in China is about 10\% of GDP (Zhou, 2011). The high frequency of haze and the great influence have attracted the attention of people from all walks of life. In 2017, Premier Li Keqiang wrote the "resolutely fighting the blue sky defence war" into the government work report.

In addition to natural factors, serious haze pollution is largely attributed to extensive economic development mode and unbalanced industrial structure. Studying and exploring the internal relationship between haze and economic growth will help in finding out the root causes of frequent haze, and put forward the regulation mechanism of coordinating air pollution and economic development represented by haze, so as to provide scientific basis and policy suggestions for regional economic development and 
ecological environmental protection, so as to achieve the goal of green development and ecological civilization construction.

The relevant research work in the world has been carried out relatively early. Many scholars have studied the relationship between haze pollution and economic growth from different perspectives, such as the formation mechanism of haze and the analysis of influencing factors, the health economic loss caused by regional particles $\left(\mathrm{PM}_{2.5}\right.$, $\mathrm{PM}_{10}$, etc.), and environmental Kuznets curve test, etc. These documents reflect the research results of this field only in one way, but it is difficult to grasp the dynamic development and hot trend of the international research field in a comprehensive way. Through the method of knowledge map, the research dynamic and development trend of professional field can be presented in the form of visual atlas (Hou et al., 2009). At present, the map of science knowledge has made great achievements in many fields, such as management, pedagogy and so on (Feng et al., 2017). However, the academic circles still lack the bibliometric analysis of the relationship between haze and economic growth. Based on this, this paper selects the bibliography of haze and economic growth in the core collection database of Web of Science (hereinafter referred to as WoS) during 1992-2017 years as the analysis data. Through CiteSpace visualization software, using knowledge mapping method and related tools, this paper makes a holistic and multi-dimensional visualization analysis of the international research on the correlation effect of haze and economic growth. The aim is to sort out the research hot spots and trends of international literature, which not only helps domestic scholars to understand the research status of the correlation between haze and economic growth in the world, track its frontier hot spots, explore and grasp the development trend and potential of this field, but also provide some reference for the haze control and ecological environmental protection in China, whether for academic research or practical.

\section{Materials and methods}

\section{Research methods}

The development of information technology and bibliometrics provides a basis for the generation of visual software. The visualization software provides a new way for document processing and analysis (Shi and $\mathrm{Li}, 2016$ ). Based on this, this paper chooses CiteSpace as the main measurement and visualization software, and Excel as an auxiliary measurement tool. Firstly, CiteSpace is used to describe the current research status and hot trend in the field of international haze and economic growth, and then the literature is read critically according to the analysis results provided by the software, so as to summarize the research topics in this field.

\section{Data sources}

In order to explore the status of international research in the area of haze and economic growth and ensure the integrity of the literature search, this paper searches relevant literature in the WoS database by means of TS $=(($ Economic OR Economy $)$ AND ( $\mathrm{PM}_{2.5}$ OR $\mathrm{PM}_{10}$ OR haze OR smog OR air quality OR air pollution). The time span is 1992-2017, and the literature types are pure scientific documents (ARTICLE), PROCEEDINGS PAPER and EDITORIAL MATERIAL, and a total of 4730 literature data are obtained. Later, using the Remove duplicates function in CiteSpace, the duplicate documents were filtered, and finally 4,225 effective records were obtained. 


\section{Results}

\section{Time distribution}

The amount of document information can reflect the heat level and research process of a certain area to some extent, which is an important part of scientific bibliometrics. According to the statistical results in WoS, the time distribution map of the literature (Fig. 1) is drawn by Excel mapping in order to understand the time distribution and growth of the literature on the related effects of haze and economic growth in the world.

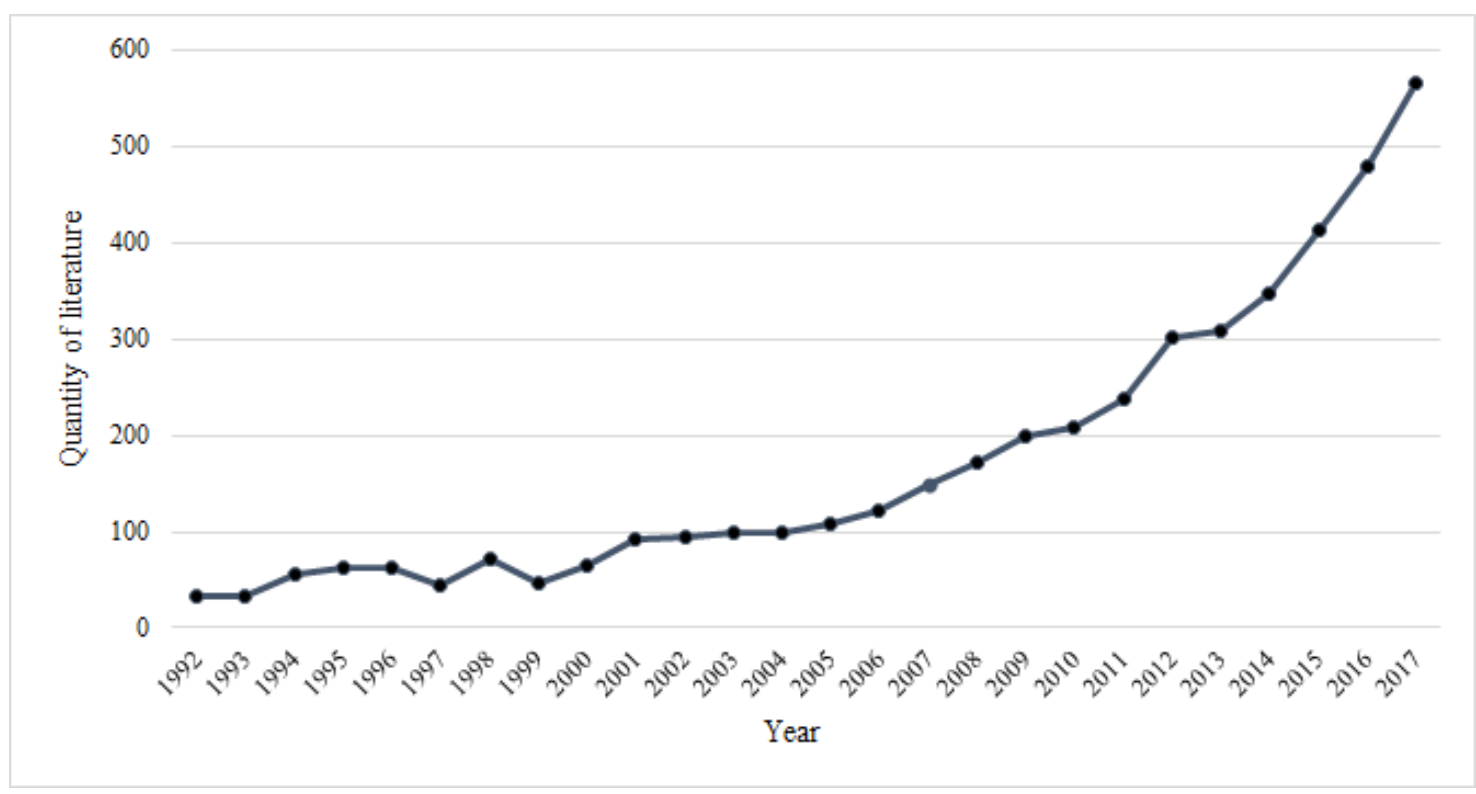

Figure 1. Time distribution of literature on correlation between haze and economic growth

As can be seen from Figure 1, the international literature on the correlation between haze and economic growth shows a relatively rapid growth trend. One of the reasons is that the number of journals on ecological environment and environmental economy is increasing, but the more important reason is that the problem of haze has become more and more serious in recent years, which has attracted extensive attention and research from scholars all over the world. According to Figure 1, the time distribution of relevant literature can be roughly divided into three stages: (1) Stage 1 (1992-2000 year): the number of literature is small, and the fluctuation range is not large, indicating that the international research in this field started very early, but the research progress is relatively slow. (2) Stage 2 (2001-2010 year): In the first half of this phase (2001-2005), the amount of literature fluctuated around 100, and it did not increase until 2006. (3) Stage 3 (2011-2017 year): the stage of rapid literature growth. Since 2011, the continuous broadcasting of $\mathrm{PM}_{2.5}$ by the US Embassy has aroused widespread social concern. Academic circles have also paid great attention to the correlation effect between haze and economic growth, and have done a lot of research on it, and achieved a lot of research results. It can be seen that the literature in this stage is gradually increasing, and the growth rate is gradually accelerating.

According to the law of the logical growth curve of literature, the growth of literature can be divided into four stages (Qiu JP, 2007). The first stage is the embryonic stage, the growth of literature is relatively slow; the second stage is the rapid growth stage, the 
literature grows sharply; the third stage is the mature stage, the growth rate is slow; the fourth stage is the saturation stage, and the literature growth rate approaches zero. From the above theory, it can be inferred that the literature on the correlation between haze and economic growth is in a state of rapid growth, so it accords with the second stage of literature development, and it is predicted that the volume of literature will remain high growth in the next few years (Sun and Wang, 2016).

\section{Spatial distribution}

In this paper, we use the co-occurrence network of the provided by CiteSpace, the co-occurrence network of research institutions, the co-citation network of the periodicals, the shared network function of the country and the region, to analyze the scientific research cooperation network in the field of haze and economic growth in the world from the micro, meso and macro levels, thus showing the spatial distribution characteristics of the field (Liu et al., 2017).

\section{Micro layer - author analysis}

1) Author's analysis: initially formed a batch of high-yielding authors

Through the analysis of the amount of the author's publications, we can understand the author's scientific research ability and level, and make a quantitative analysis of the author's publications in the field of the correlation effect haze and economic growth, and can get the international high-yielding author group in this field (Liu et al., 2011).

According to Table 1, the most frequently published research topic in the field of haze and economic growth is the Huang GH of North China Electric Power University, who has published 32 articles. According to Price formula (Eq. l):

$$
M=0.749 *\left(\mathrm{~N}_{\max }\right)^{1 / 2}
$$

$\mathrm{M}$ is the number of papers, $\mathrm{N}_{\max }$ refers to the number of the highest producers, the authors who have published more than $\mathrm{M}$ are called high-yielding authors (Sun and Wang, 2016). This paper calculates the threshold of high-yielding authors in the field of correlation between haze and economic growth, which is 4.24. Therefore, this paper takes the author whose articles are more than or equal to 5 to be a high-yielding author. There are 46 high-yielding authors (Table 1). These high-yielding authors are relatively active in the research field, and have strong scientific research ability. Altogether 397 papers are published, accounting for $9.40 \%$ of the total. This indicates that a certain number of high-yielding authors have been formed to some extent in the field of international academia.

2) Author cooperation analysis: high-yielding authors gathered and the rest of the authors dispersed and coexist

In order to identify the core scholars in the research field and their mutual cooperation strength, the author analyzes the literature from the perspective of author's co-occurrence.

In CiteSpace, the time zone is selected from 1992-2017, the time slice is 2, the threshold is "Top $\mathrm{N}=30$ ", the other parameters use the default value, Node Types selects the Author, and generates Figure 2. Figure 2 shows that there are 296 nodes and 
303 connections in the map, and the density is 0.0069 . The node in the map represents the author, the size of the node indicates the author's volume of publications, and the thickness and color of the connection indicate the strength of the cooperation relationship and the year in which the co-occurrence relationship first occurred (Chen et al., 2014).

Table 1. High-yielding author statistics (Number of documents $\geq 5$ )

\begin{tabular}{c|c|c|c|c|c}
\hline $\begin{array}{c}\text { Number of } \\
\text { documents }\end{array}$ & Name & $\begin{array}{c}\text { The year of the } \\
\text { first paper }\end{array}$ & $\begin{array}{c}\text { Number of } \\
\text { documents }\end{array}$ & Name & $\begin{array}{c}\text { The year of the } \\
\text { first paper }\end{array}$ \\
\hline 32 & Huang GH & 2008 & 6 & Carmichael GR & 1999 \\
25 & Zhang Q & 2010 & 6 & Chen L & 2006 \\
21 & Wang Y & 2010 & 6 & Li L & 2016 \\
18 & Liu Y & 2010 & 6 & Beig G & 2008 \\
15 & Zhang Y & 2012 & 6 & Hao Y & 2016 \\
13 & Li Y & 2006 & 6 & Hao JM & 2010 \\
12 & Zaman K & 2014 & 6 & Rojas-Rueda D & 2016 \\
12 & Streets DG & 1999 & 6 & Chen JM & 2016 \\
12 & Zhou Y & 2010 & 5 & Dincer I & 1998 \\
11 & Brajer V & 2004 & 5 & Liu XJ & 2016 \\
10 & Li YP & 2008 & 5 & An XQ & 2010 \\
9 & Guan DB & 2014 & 5 & Li J & 2016 \\
9 & Zhao Y & 2010 & 5 & Huo H & 2014 \\
9 & Wang L & 2014 & 5 & Levy JI & 2005 \\
8 & Wang SX & 2014 & 5 & Bi J & 2010 \\
8 & Liao H & 2012 & 5 & Nam KM & 2008 \\
8 & Li W & 2012 & 5 & Amann M & 1999 \\
8 & Mead RW & 2004 & 5 & Zhang J & 2014 \\
7 & Wang J & 2013 & 5 & Guttikunda SK & 2014 \\
7 & Zhu Y & 2014 & 5 & He LY & 2016 \\
7 & Smith KR & 2004 & 5 & Millimet DL & 2003 \\
7 & He KB & 2014 & 5 & Scasny M & 2010 \\
6 & Paltsev S & 2008 & 5 & List JA & 2003 \\
\hline
\end{tabular}

As shown in Figure 2, a number of nodes are concentrated in the center of the map, and there are many connections between these nodes; at the same time, many isolated nodes are dispersed around it. It shows that there are different degrees of cooperation between the authors of the central region, and the flow of knowledge between each other is better, but the authors in the scattered parts around them lack communication and cooperation and are in a state of isolation. At the same time, most of the node connections in the center of the original map are orange red (corresponding to 20122017 year). It shows that the cooperative group has been formed in the last five years. It is now in the stage of strengthening communication and deepening the cooperation. It is expected that the future part of the author will create more research results through cooperation. 


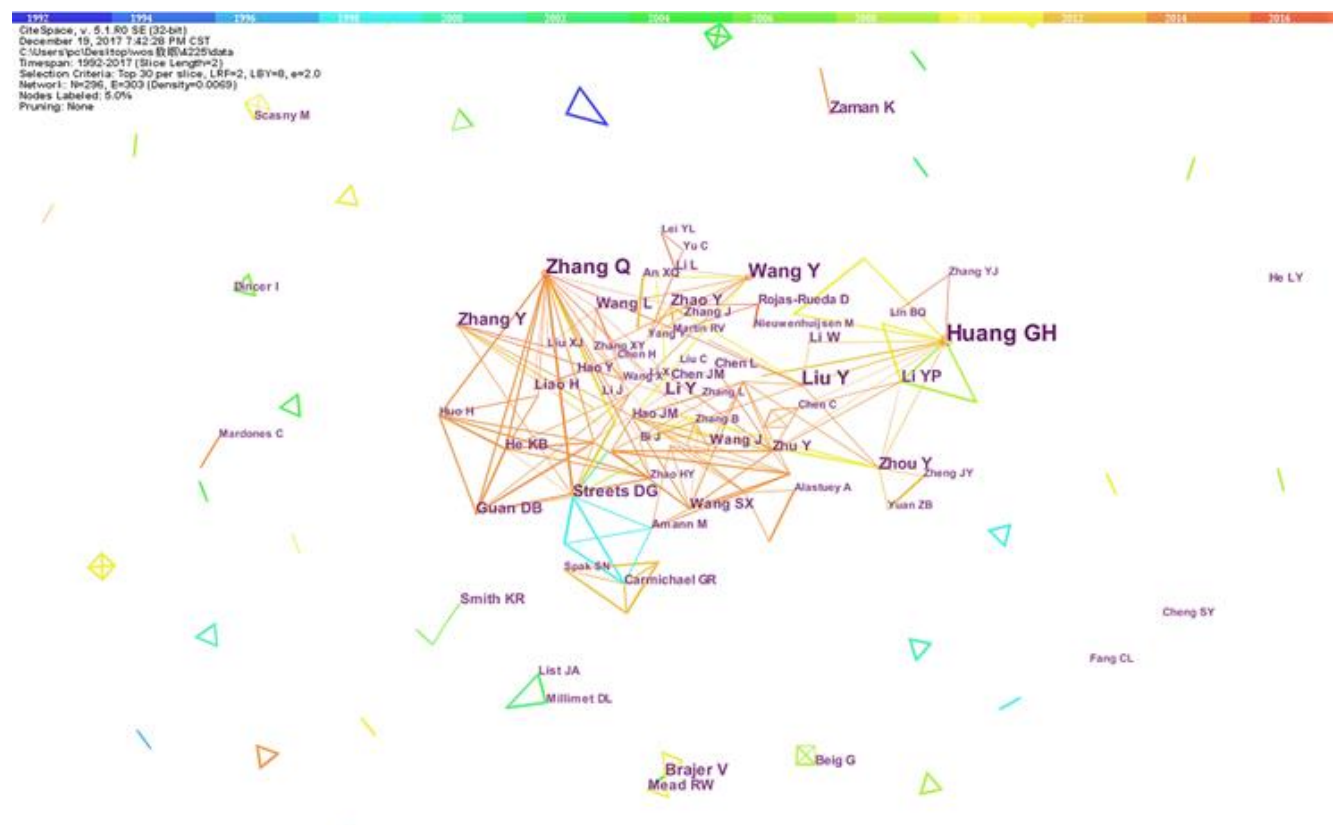

Figure 2. Co-occurrence map of scholars

Meso level - research institutions and periodicals analysis

1) Cooperation analysis of research institutions: focusing on top international universities and research institutes

Research institutes can identify the status and importance of each research institution in the field, and the degree of cooperation between them (Liu et al., 2017). In order to make the map display more concise and clear, the time slice is 4, the threshold "Top 5\% per slice" is selected, and the image is "pruned" using the minimum spanning tree algorithm (MST), and Figure 3 is obtained. As shown in the following figure, there are 165 nodes and 194 connections. The overall density of the network is 0.0143 . Table 2 lists the detailed information of the top 20 institutions.

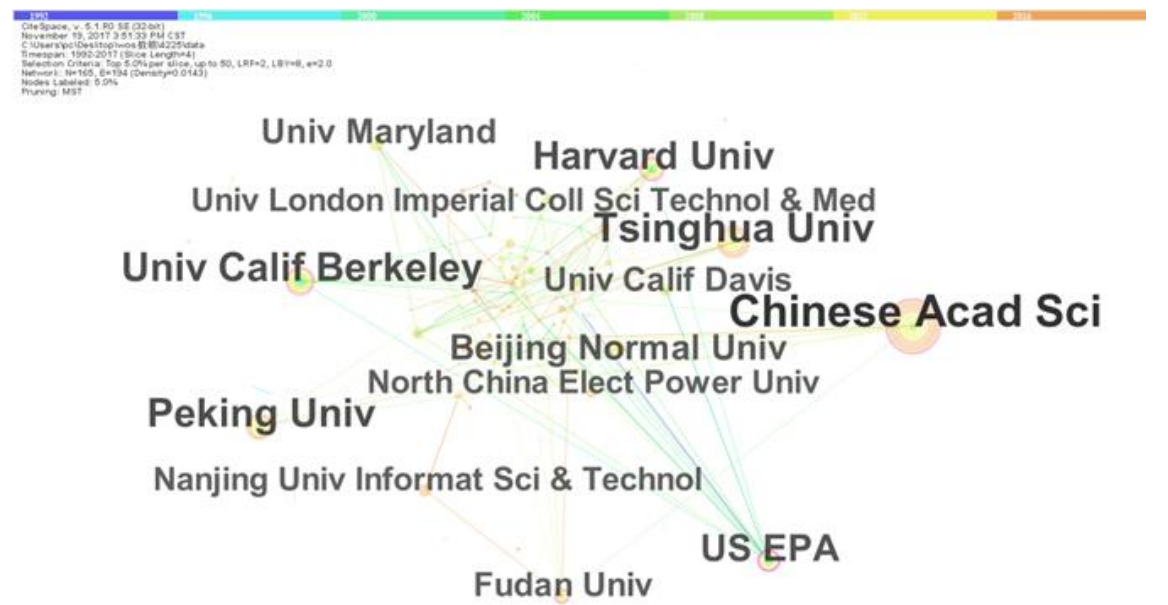

Figure 3. Co-occurrence map of institutions 
Combined with the analysis of Figure 3 and Table 2, we can see: (a) the research power of the correlation between haze and economic growth is concentrated in universities and research institutes. Tsinghua University, Univ Calif Berkeley, Peking University and Harvard University are among the top international universities with environmental and economic advantages. The largest node is the Chinese Acad Sci. Its scientific research level is highly recognized both in China and internationally. (b) There are many connections in the central area of Figure 3, and there are scattered nodes in the non-central area. It shows that most of the research institutions in this field work closely, but there are still some institutions that lack cooperation, which should continue to strengthen exchanges and cooperation between institutions.

Table 2. Top 20 institutional information

\begin{tabular}{c|c|c}
\hline Frequency & Institution & Country \\
\hline 124 & Chinese Acad Sci & China \\
81 & Tsinghua Univ & China \\
71 & Univ Calif Berkeley & U.S.A \\
71 & Peking Univ & China \\
64 & Harvard Univ & U.S.A \\
55 & US EPA & U.S.A \\
43 & Beijing Normal Univ & China \\
37 & Univ Maryland & U.S.A \\
36 & Univ Calif Davis & U.S.A \\
34 & Fudan Univ & China \\
31 & Univ London Imperial Coll Sci Technol \& Med & Britain \\
31 & Nanjing Univ Informat Sci \& Technol & China \\
31 & North China Elect Power Univ & China \\
30 & Univ N Carolina & U.S.A \\
29 & Nanjing Univ & China \\
28 & Univ Illinois & U.S.A \\
26 & Univ Michigan & U.S.A \\
26 & MIT & U.S.A \\
25 & Univ Utrecht & Netherlands \\
25 & Chinese Acad Sci & \\
\hline
\end{tabular}

2) Co-cited analysis of journals: research results concentrate on six high level journals

The "Cited Journal" function is selected to reflect the relevance between the various journals and disciplines by the phenomenon that the two journals are cited by the same document, so as to further analyze the knowledge base distribution in the area of haze and economic growth (Chen et al., 2014). The parameter is set to Top $\mathrm{N}=10$, and MST is selected for pruning to highlight its main components.

As shown in Figure 4A, the journal co citation map has 148 nodes and 355 connections. The density is 0.0326 , and there are many nodes in the annual ring. Combined with the analysis of background data, the six journals of "Atmospheric Environment", "Environmental Science \& Technology", "Environmental Health Perspectives", "Energy Policy", and "Science of the Total Environment" and "Science" have concentrated most of the research literature on the association effects of haze and 
economic growth. The related papers are of academic value, data value and applied value, representing the research hotspots and frontiers in this field. Among the representative journals, the impact factors of "Science", "Environmental Health Perspectives" and "Environmental Science \& Technology" from 2016 to 2017 are larger, and the impact factor of Science is even as high as 37.205, which is one of the most authoritative academic journals in the world. All of these show that the correlation between haze and economic growth has received international attention.

Then, through the Spotlight function in CiteSpace, the nodes with high centrality (purple circle nodes) are highlighted (Fig. 4B). It can be found that the number of nodes with purple circles in the journal's co-citation map is relatively large. Among them, the intermediary centrality of "Science" and "Energy Policy" is more than 0.2 , indicating that these journals are in the key position in the network, which is the object that scholars in this field should focus on (Liu et al., 2017).

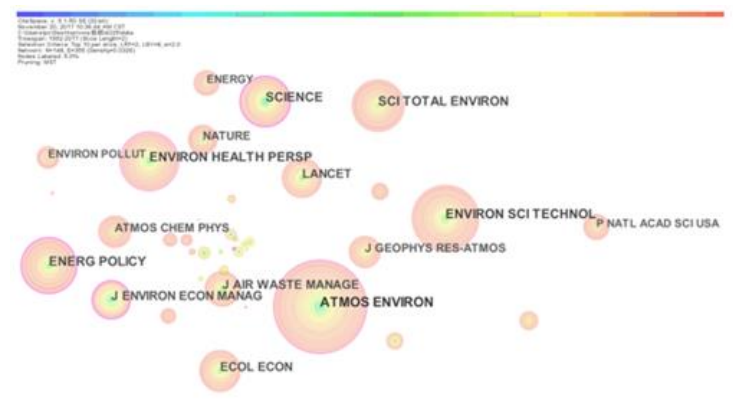

(A)

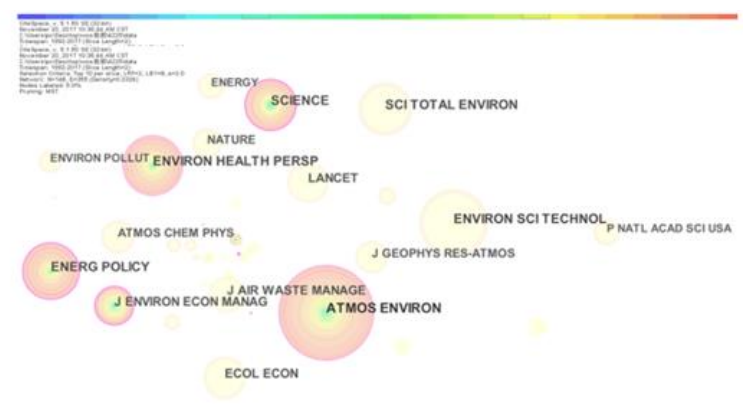

(B)

Figure 4. Co-citation map of journals

The macro level - national co-occurrence analysis: "USA-China", "Holland-FranceItaly-Spain" are two largest emerging cooperatives

At the macro level, through the analysis of the national cooperation network, we can understand whether there is a cooperation relationship and the intensity of cooperation among the countries in the field of the correlation effect between haze and economic growth. Therefore, the node selects "Country", the parameter is set to Top $\mathrm{N}=10$, and the time slice is 2, the result is shown in Figure 5.

From the background data analysis of Figure 5, 28 countries have published more than 3 papers in the field of the correlation between haze and economic growth, but a large number of documents are obviously concentrated in a few countries. The data show that there are five countries with more than 200 papers, but the total number of papers in these five countries is up to 2941 , that is, nearly $70 \%$ papers in this field are produced from these countries. Among them, the United States has a very obvious advantage, with a total of 1382 (32.71\% of the total), and the centrality is as high as 0.55, indicating that the United States is in a key dominant position in the field of haze and economic growth, with a high achievement and outstanding contribution. China's paper output ranks second, with a total of 770, followed by the UK (a total of 334 articles), Canada (a total of 247 articles) and Germany (a total of 208 articles). In Figure 5, the thickness of the connection indicates the strength of the cooperation. The color of the line in the original figure indicates the time of cooperation between 
countries. Based on this, it can be concluded that "the United States-Canada" and "Canada-Germany" had close cooperation in the early period (1992-2000). "The United Kingdom-Canada-China" had strong cooperation in the medium term (2001-2008), while the two cooperation bodies of "the USA-China" and "Holland-France-ItalySpain" were formed in recent years (2009-2017).

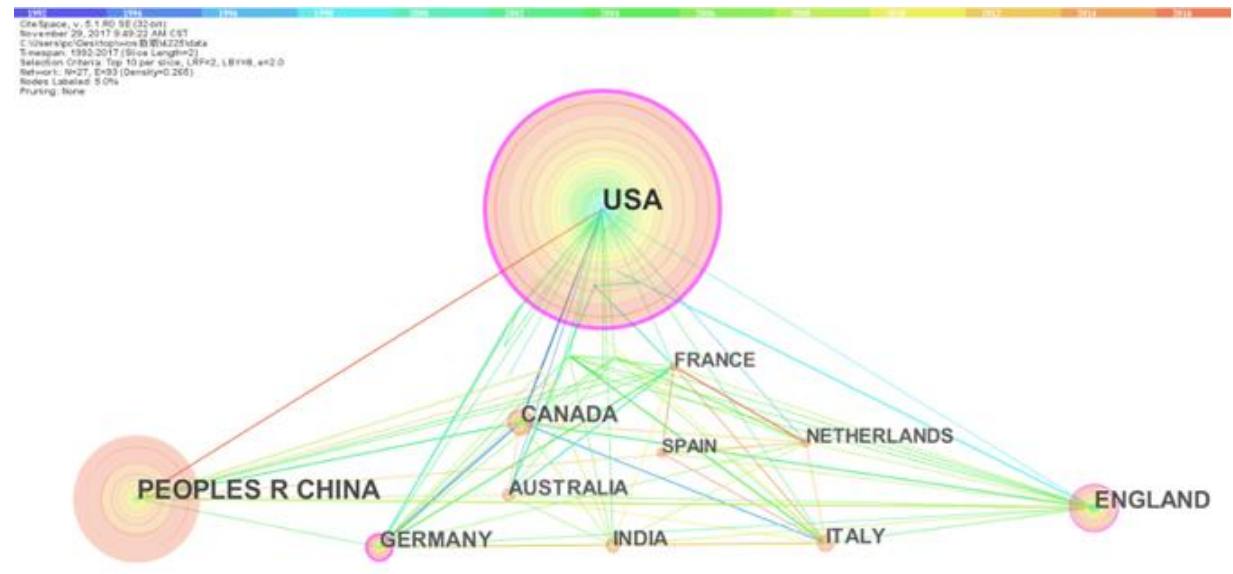

Figure 5. National cooperation network map

From the analysis of Figure 5, we can see that the research power in the field of the correlation effect between haze and economic growth in the world is mainly concentrated in the developed countries such as the USA and the UK, as well as the rapidly developing countries such as China, indicating that these countries are more concerned with the field relative to other countries and have corresponding researchers. At the same time, Figure 5 shows that there are many links between countries, indicating that their cooperation and exchange are relatively close, which is conducive to the in-depth research in this field and the output of more scientific research results. However, the original map shows that the connection between some countries is a tone, indicating that the cooperation between these countries only existed for a period of time, and has not always maintained cooperation. In the future, countries should strengthen continuous contacts and exchanges, maintain long-term cooperation so as to further promote sustainable development in this field.

\section{Discussion}

\section{Research topics}

From the previous analysis, we can see that the research literature on the correlation between haze and economic growth is very rich, but the research topic is more scattered. Combined with the high-frequency keyword clustering processed by CiteSpace (Table 3), and reading and sorting out the existing literature, the author divides the research topics into four aspects: (1) the economic mechanism of haze formation; (2) the relationship between haze and economic growth; (3) the spatial spillover effect of haze; (4) the countermeasures of haze control. 


\section{The economic mechanism of haze formation}

Some scholars believe that energy and industrial structure and other factors have led to the emergence of haze weather. Jessie (2006) found that when entering the heavy industry stage, the consumption of coal increased continuously, the $\mathrm{PM}_{2.5}$ concentration also increased, and the air pollution problem became more and more serious. Wang et al. (2015) found that the aggravation of haze pollution is mainly caused by the rising consumption of coal energy in industrial production. Improving industrial structure is an important way to control haze. Antonakakis (2017) analyzed the relationship between carbon emissions and economic growth, and found that the increase of global carbon emissions is accompanied by rapid economic growth.

However, some scholars have raised questions and conducted research: Antweiler (2001) established a theoretical model and used the data of $\mathrm{SO}_{2}$ concentration to test the theory, and finally came to the conclusion that more free trade seems to be favorable to the environment. He (2012) analysed the impact of the three heavy transformation processes on the environment, such as marketization, globalization and decentralization, and concluded that the marketization and decentralization are harmful to the urban environment, while the economic globalization is beneficial to the urban air quality.

\section{The relationship between haze and economic growth}

\section{1) Empirical research based on EKC}

Panayotou (1993) applied the Kuznets curve to the analysis of the relationship between environmental quality and economic growth, and proposed the $\mathrm{EKC}$ hypothesis (an inverted U-shaped relationship between environmental pollution and economic growth) for the first time. Selden and Song (1994) analyzed and found that the per capita emissions of suspended particulate matter, $\mathrm{SO}_{2}, \mathrm{NOx}$ and $\mathrm{CO}$ had a reverse relationship with GDP per capita. They believed that although emissions would be reduced in the long run, it was expected that global emissions would continue to grow rapidly in the next few decades. Grossman and Krueger (1994) found that economic growth brought about environmental deterioration in the early stages of economic growth and improvement in the later stages; and the turning points of different pollutants were different.

With the deepening of research, different voices have emerged in academia: Ansuategi (2003), by analyzing the panel data of $\mathrm{SO}_{2}$ emissions in Europe, proposed that EKC would be established only when the pollutants are semi-local and have medium-term effects. Stern (2004) pointed out that there are some problems in EKC hypothesis, such as omission of variable bias, heteroscedasticity and endogeneity. Dinda (2004) combed the related literature, background history and conceptual insights, and summarized two general explanations for the formation of EKC. At the same time, there were some doubts about EKC from the perspective of concept and method. However, Tamazian and Rao (2010) considered the questions raised by the predecessors and examined them again. The results still showed the environmental Kuznets hypothesis was valid.

Hao and Liu (2016) used spatial error model and spatial lag model to analyze the direct relationship between $\mathrm{PM}_{2.5}$ and economic development. The results show that the relationship between $\mathrm{PM}_{2.5}$ and per capita GDP is inverted U-shaped. Secondary industry has a significant positive impact on urban $\mathrm{PM}_{2.5}$ concentrations. Sarkodie et al. (2019) concluded that the per capita $\mathrm{PM}_{2.5}$ emissions and income levels showed an 
inverted U-shaped curve, which confirmed the validity of the Kuznets curve hypothesis between air pollution and urbanization.

\section{2) Theoretical research}

Compared with empirical analysis, the theoretical research in this field is relatively weak: Bovenberg and Smulders (1993) explored the relationship between environmental quality and economic growth in the endogenous economic growth model under the technological change driven by pollution. Chichilnisky (1994) put the environment and pollution into the neoclassical production function and utility function to analyze, and believed that the different property rights created different regional trade motives.

\section{The spatial spillover effect of haze}

Many scholars in the world believe that the haze pollution in a certain region will affect the environmental quality of the surrounding areas, and its governance will also affect the surrounding areas. That is, there is a spatial spillover effect of haze. Therefore, it is necessary to explore the relationship between the environment and the economy in the space framework, although it will make the relationship more complex.

In the early twenty-first Century, Anselin (2001), a famous international econometric economist, applied the spatial econometric modeling method to the perspective of environment and resource economy, and studied the importance of spatial factor analysis. Maddison (2007) selected $\mathrm{SO}_{2}, \mathrm{NO}_{2}$ and other pollutants as the typical measure of air quality, and used the spatial econometric method to establish a model. It was found that there was a spillover effect on the pollution and governance of haze between countries under this model. Poon et al. took Chinese provinces as the research object. By simulating the impact of energy, transportation and trade on local air pollution emissions, it was confirmed that spillover effect did exist in Chinese provinces Poon et al. (2006). Hosseini and Kaneko (2013) used six kinds of weight matrices to create six spatial models, demonstrating that air pollution does have spillover effects between countries. Dimitriou and Kassomenos (2014) studied the origin of $\mathrm{PM}_{2.5}$ in Rome and its impact on air quality, indicating that pollutants have potential external spillover effects.

\section{The countermeasures of haze control}

According to the policy connotation reflected by EKC, economic growth will ultimately help improve environmental quality, and pollution is only a "by-product" on the growth path (Lu and Sun, 2015). However, accelerating economic growth is not a panacea for improving environmental quality (Arrow et al., 1995). Grossman and Krueger (1995) believed that the effective way to solve the environmental problems is to improve the technology and optimize the industrial structure. Based on the theory of sustainable development, Karki (2005), taking the ASEAN region as an example, believed that in order to maintain sustainable development under the condition of growing economy, comprehensive management of resources and energy was needed. Ma et al. (2019) analyzed haze in eastern and northern China, and believed that emission reduction and regional joint prevention and control would help improve air quality. 
Some scholars use the Computable General Equilibrium (CGE) model to study the methods and countermeasures of haze control. Jie (2005) established a static CGE model, and found that under the policy of flue gas desulfurization, the economic growth rate will decrease, and clean energy will be used instead of polluting energy to achieve the purpose of reducing pollution. Based on the CGE model, scholars such as Xu (2009) and Allan (2014) have proposed the idea of using tax tools, including sulfur taxes and carbon taxes, to control haze. Chander (2018) proposed to strengthen the current policy system to solve the haze problem in Indonesia, including the implementation of various tax laws.

\section{Research hotspots and trend analysis}

\section{Research hotspots}

Keyword co-occurrence network can reflect the current research hotspots in a certain field. Based on this, the network node of CiteSpace is selected as "Keywords", the time slice is 3, the threshold is set to "Top $10 \%$ per slice, up to 30 ", and the Pathfinder algorithm is selected to be simplified. After that, the clustering analysis is carried out, and key words are extracted with LLR (logarithmic likelihood algorithm) as the clustering identifiers. The results are shown in Figure 6 and Table 3.

The upper left corner of Figure 6 shows that the $\mathrm{Q}$ value of the co-occurrence network of haze and economic growth is $0.5682 \geq 0.3$, and the $S$ value is close to 0.5 , which indicates that the network structure is significant and the result is basically reasonable. The graph has 221 nodes and 424 connections, with a density of 0.0174 . The greater the node is, the higher the number of occurrences is. The nodes with purple outer ring will play an important role in the network. In this paper, the keywords with intermediary centrality $(\geq 0.1)$ are selected to explore the research hotspots in various fields in the different periods, as shown in Table 4.

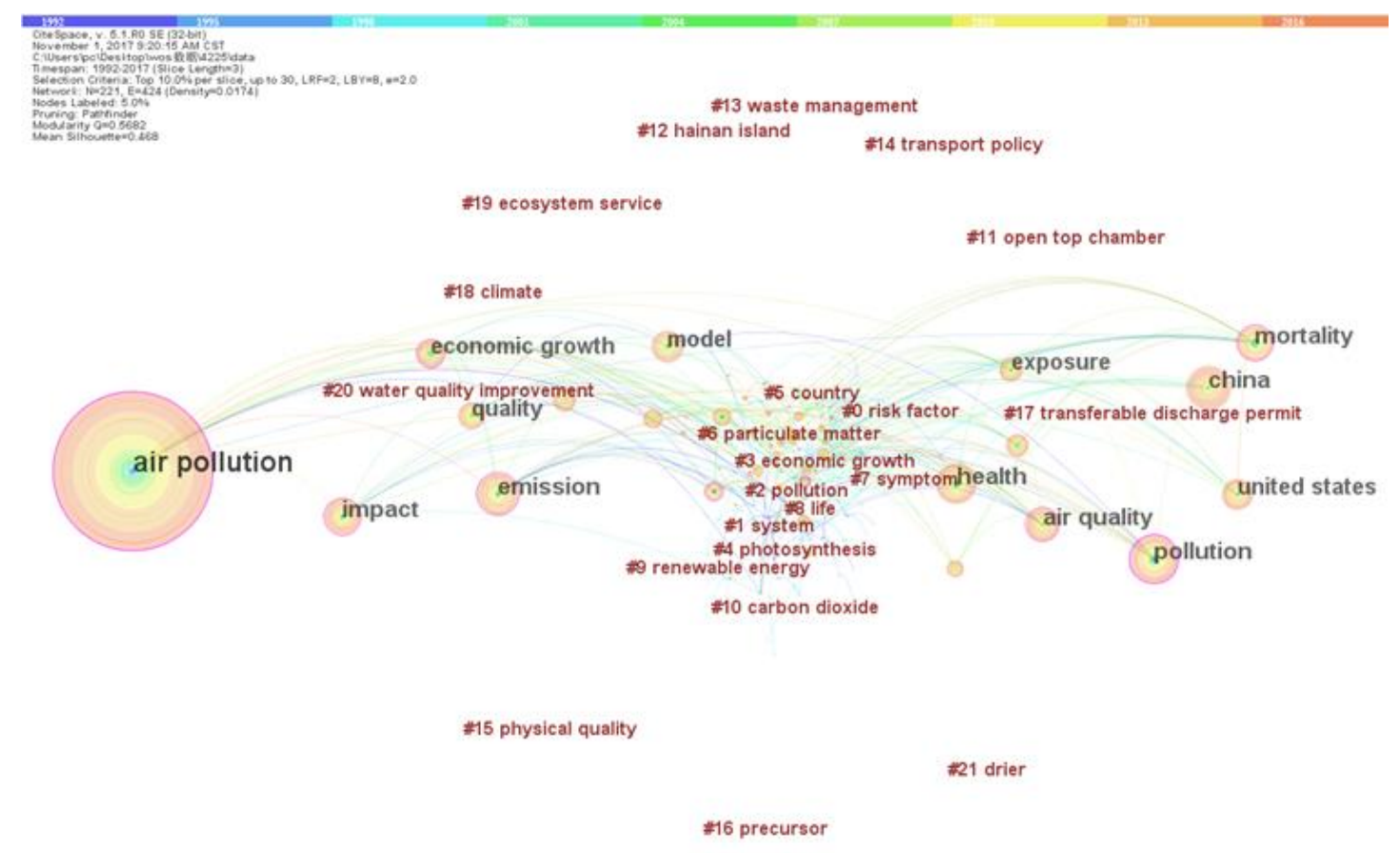

Figure 6. Keywords co-occurrence map 
Table 3. Keywords clustering

\begin{tabular}{c|c|c|c|c}
\hline $\begin{array}{c}\text { Serial } \\
\text { number }\end{array}$ & $\begin{array}{c}\text { Cluster } \\
\text { size }\end{array}$ & $\begin{array}{c}\text { The tightness of } \\
\text { clustering }\end{array}$ & Label & High frequency keywords \\
\hline 0 & 39 & 0.617 & Risk factor & Health(313); mortality(275); exposure(203) \\
\hline 1 & 27 & 0.7 & System & $\begin{array}{c}\text { Climate change(179); energy(153) } \\
\text { performance(112) }\end{array}$ \\
\hline 2 & 26 & 0.549 & Pollution & China(330); impact(277); air quality(272) \\
\hline 3 & 24 & 0.723 & $\begin{array}{c}\text { Economy } \\
\text { growth }\end{array}$ & $\begin{array}{c}\text { Emission(328); policy(165) environmental } \\
\text { Kuznets curve(113) }\end{array}$ \\
\hline 4 & 19 & 0.808 & Photosynthesis & $\begin{array}{c}\text { Acidification(14); deposition(8); critical } \\
\text { load(7) }\end{array}$ \\
\hline 5 & 17 & 0.76 & Country & CO $_{2}$ emission(103); consumption(46); \\
lead(15)
\end{tabular}

Table 4. Keywords with intermediary centrality $\geq 0.1$

\begin{tabular}{c|c|c|c|c|c|c|c}
\hline $\begin{array}{c}\text { Serial } \\
\text { number }\end{array}$ & Frequency & Centrality & Key word & $\begin{array}{c}\text { Serial } \\
\text { number }\end{array}$ & Frequency & Centrality & Keywords \\
\hline 1 & 1076 & 0.45 & Air pollution & 8 & 228 & 0.14 & Quality \\
2 & 365 & 0.23 & Pollution & 9 & 203 & 0.14 & Exposure \\
3 & 328 & 0.22 & Emission & 10 & 313 & 0.13 & Health \\
4 & 330 & 0.19 & China & 11 & 270 & 0.12 & Air quality \\
5 & 275 & 0.18 & Mortality & 12 & 108 & 0.11 & System \\
6 & 52 & 0.18 & Children & 13 & 175 & 0.1 & Particulate matter \\
7 & 153 & 0.15 & Energy & 14 & 5 & 0.1 & Acid rain \\
\hline
\end{tabular}

According to the map analysis, the keywords "air pollution", "pollution", "emission", "mortality" and "China" are ranked in the top five, and their co-occurrence frequency is more than 200 times. These keywords with high frequency and centrality represent the issues that researchers have paid close attention to and conducted a lot of research during this period, and play a key pivotal role in the study of the correlation effect between haze and economic growth.

\section{Trend analysis}

Timezone view focuses on the evolution trend of research topics over time and their impact on each other. Therefore, the timezone view of keyword co-occurrence network can show the hot trends in the field of the correlation between haze and economic growth in the world. The network node is selected as "Keywords", the time slice is 3, the threshold is set to "Top $\mathrm{N}=20$ ", and the MST algorithm is selected for pruning to get the main hot trends in this field. Finally, the time map of the keyword evolution since 1992 is obtained (Fig. 7). 


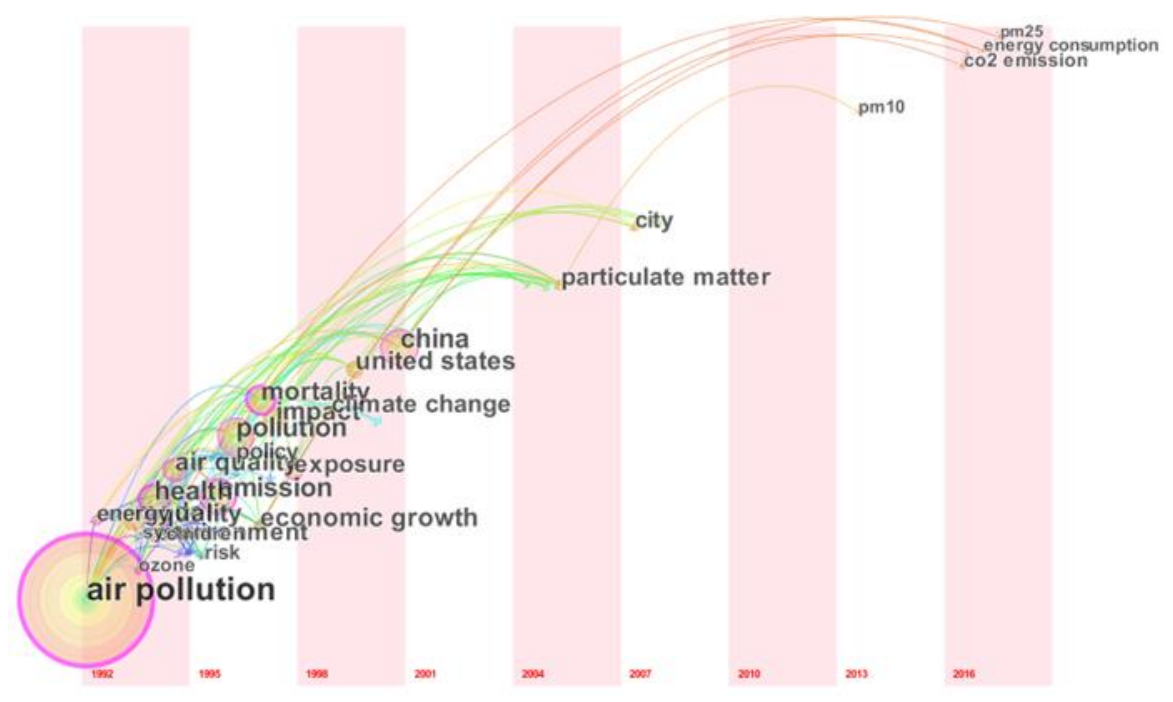

Figure 7. Keywords time zone map

Through the analysis of Figure 7 and its background data, there are many key words in the early stage of the evolution of the correlation between haze and economic growth, such as "air pollution", "health", "economic growth" and "energy". These keywords are the most important focus of the academic community on the correlation between smog and economic growth in the 1990s. Since the 21st century, keywords such as "China", "particulate matter", "city" and " $\mathrm{PM}_{2.5}$ " " $\mathrm{CO}_{2}$ emission" have attracted wide attention and become the current research hotspot in this field, which may continue to be hot in the future. On the whole, Figure 7 shows the trend of international research on haze and economic growth.

\section{Conclusion}

In view of the fact that the current research has not yet fully demonstrated the development of international research on the correlation between haze and economic growth, and the lack of scientific visual quantitative analysis, this paper systematically analyzed the research on the correlation effect between haze and economic growth by using knowledge map method and CiteSpace tool. The time distribution of the literature in this field is distributed. The author's publications and cooperation in this field is analyzed by using the co-occurrence map of the author. Through the analysis of the research institutions, national co-occurrence and co-cited of journals, the main research forces in the field and the high level journals are found. The research hotspots and trends in this field are explored by using the keyword co-occurrence map and time zone map.

The main conclusions are as follows: (1) In the past sixteen years, the international academia has paid more and more attention to the correlation effect between haze and economic growth, and the literature in this field is increasing. According to the four stages of the logical growth curve of the literature, we can see that it is now in the $T_{1}-T_{2}$ period (rapid development stage), which has abundant research results, and the growth rate of the literature volume remains relatively high. (2) At the international level, a group of high-yielding authors headed by Huang Guohe of North China Electric Power 
University, has been formed in this field, and the cooperation between these highyielding authors is closer in the last five years and is in the stage of deepening cooperation. But the other authors lack communication and are in a state of isolation. (3) The main research forces in the field are concentrated in the international top universities and scientific research institutes. "The USA-China" and "Holland-FranceItaly-Spain" are the main cooperation bodies in recent years. (4) Literature with great value in this field in the world is mainly concentrated on "Science", "Environmental Health Perspectives" and "Environmental Science \& Technology". The related papers in these journals represent the hot and frontier research in this field, and have high academic value. (5) The research topics in this field mainly include the economic mechanism of haze formation, the relationship between haze and economic growth, the spatial spillover effect of haze and the countermeasures for haze control. (6) Keywords such as "air pollution", "health", "economic growth" and "energy" have been released in the early stage of the field. Since the 21 st century, "China", "particulate matter", "city", "PM 2.5 " and " $\mathrm{CO}_{2}$ emission" have become the research hotspots.

In short, from the perspective of economic growth, the phenomenon of haze can be studied in many aspects. However, from the perspective of system theory and scientific development concept, the existing research still has the following shortcomings: (1) In terms of research content, there are many studies on the causes and countermeasures of haze, but little attention has been paid to the transmission mechanism of haze and its relationship with economic growth, especially the lack of theoretical research on this issue; (2) In terms of research methods, the normative analysis of haze and economic activities is more, but the empirical analysis of spatial statistics and econometrics is relatively lacking. Therefore, as a hot research topic in the interdisciplinary field of environment and economy, the use of spatial statistics and econometric methods to study whether haze and economic growth are related, and what kind of correlation exists is a further research direction in the future.

Acknowledgements. This work is supported by the National Social Science Foundation of China (grant number 15CJL029).

\section{REFERENCES}

[1] Allan, G., Lecca, P., Mcgregor, P., Swales, K. (2014): The economic and environmental impact of a carbon tax for Scotland: a computable general equilibrium analysis. Ecological Economics 100: 40-50.

[2] Anselin, L. (2001): Spatial effects in econometric practice in environmental and resource economics. - American Journal of Agricultural Economics 83: 705-710.

[3] Ansuategi, A. (2003): Economic growth and transboundary pollution in Europe: an empirical analysis. - Environmental \& Resource Economics 26: 305-328.

[4] Antonakakis, N., Chatziantoniou, I., Filis, G. (2017): Energy consumption, $\mathrm{CO}_{2}$, emissions, and economic growth: an ethical dilemma. - Renewable \& Sustainable Energy Reviews 68: 808-824.

[5] Antweiler, W., Copeland, B. R., Taylor, M. S. (2001): Is free trade good for the environment? - American Economic Review 91: 877-908.

[6] Arrow, K., Bolin, B., Costanza, R., et al. (1995): Economic growth, carrying capacity, and the environment. - Science 268: 520. 
[7] Bovenberg, A. L., Smulders, S. (1993): Environmental quality and pollution-augmenting technological change in a two-sector endogenous growth model. - Journal of Public Economics 57: 369-391.

[8] Chander, P. (2018): A political economy analysis of the Southeast Asian haze. Singapore Economic Review 63: 1085-1100.

[9] Chen, Y., Chen, C. M., Hu, Z. G. (2014): Principles and Applications of Analyzing a Citation Space. - Science Press, Beijing.

[10] Chichilnisky, G. (1994): North-south trade and the global environment. - American Economic Review 84: 851-874.

[11] Dimitriou, K., Kassomenos, P. (2014): Indicators reflecting local and transboundary sources of $\mathrm{PM}_{2.5}$ and PMCOARSE in Rome-impacts in air quality. - Atmospheric Environment 135: 69-86.

[12] Dinda, S. (2004): Environmental Kuznets curve hypothesis: a survey. - Ecological Economics 49: 431-455.

[13] Feng, X. L., He, S., Xiong, T. C., Wu, Q. H., L, Y. J. (2017): Comparison and analysis of mapping knowledge domain and Google knowledge graph; based on the theory of knowledge management. - Journal of Intelligence 36: 149-153.

[14] Grossman, G. M., Krueger, A. B. (1994): Economic Growth and the Environment. Quarterly Journal of Economics 110: 353-377.

[15] Grossman, G. M., Krueger, A. B. (1995): Economic Growth and the Environment. Springer, Netherlands.

[16] Hao, Y., Liu, Y. (2016): The influential factors of urban $\mathrm{PM}_{2.5}$ concentrations in China: a spatial econometric analysis. - Journal of Cleaner Production 112: 65-80.

[17] He, C., Pan, F., Yan, Y. (2012): Is economic transition harmful to China's urban environment? Evidence from industrial air pollution in Chinese cities. - Urban Studies 49: 1767-1790.

[18] Hosseini, H. M., Kaneko, S. (2013): Can environmental quality spread through institutions? - Energy Policy 56: 312-321.

[19] Hou, H. Y., Liu, Z. Y., Luan, C. J. (2009): Quantitative analysis on the research front of international scientometrics: based on mapping of knowledge. - Science Research Management 30: 164-170.

[20] Jie, H. E. (2005): Estimating the economic cost of China's new desulfur policy during her gradual accession to WTO: the case of industrial $\mathrm{SO}_{2}$ emission. - China Economic Review 16: 364-402.

[21] Karki, S. K., Mann, M. D., Salehfar, H. (2005): Energy and environment in the ASEAN: challenges and opportunities. - Energy Policy 33: 499-509.

[22] Liu, N. B., Ruan, X. P., Sun, L. Z. (2011): Bibliometrics analysis on information organization research in China. - Journal of Modern Information 31: 100-103.

[23] Liu, X. X., Zhang, G. Y., Tan, R. J., Ma, W. C. (2017): Foreign sustainable transformation theory research context and hotspot detection: based on the perspective of scientific knowledge. - Journal of South China Normal University (Social Science Edition) 5: 86-97 + 190-191.

[24] Lu, H., Sun, H. C. (2015): Spatial characteristics of smog pollution and associated effects on economic growth. - Fujian Forum·Humanities and Social Sciences Edition 9: 44-51.

[25] Ma, T., Duan, F., He, K., Qin, Y., Tong, D., Geng, G. (2019): Air pollution characteristics and their relationship with emissions and meteorology in the Yangtze River Delta region during 2014-2016. - Journal of environmental sciences 83:8-20.

[26] Maddison, D. (2007): Modelling sulphur emissions in Europe: a spatial econometric approach. - Oxford Economic Papers 59: 726-743.

[27] Panayotou, T. (1993): Empirical tests and policy analysis of environmental degradation at different stages of economic development. - International Labour Organization.

[28] Poon, J. H., Casas, I., He, C. F. (2006): The impact of energy, transport, and trade on air pollution in China. - Eurasian Geography \& Economics 47: 568-584. 
[29] Qiu, J. P. (2007): Information Metrology. - Wuhan University Press, Wuhan.

[30] Sarkodie, S. A., Strezov, V., Jiang, Y. (2019): Proximate determinants of particulate matter $\left(\mathrm{PM}_{2.5}\right)$ emission, mortality and life expectancy in Europe, Central Asia, Australia, Canada and the US. - The Science of the Total Environment 683:489-497.

[31] Selden, T. M., Song, D. (1994): Environmental quality and development: is there a Kuznets curve for air pollution emissions? - Journal of Environmental Economics \& Management 27: 147-162.

[32] Shi, X. C., Li, M. L. (2016): The hotspots and trends of international literature research on MOOC from 2013-2015: a visualized analysis based on citespace. - Open Education Research 1: 90-99.

[33] Stern, D. I. (2004): The rise and fall of the environmental Kuznets curve. - World Development 32: 1419-1439.

[34] Sun, R. Y., Wang, X. (2016): Analysis on the status of the internet of things in China based on the bibliometrics statistical methods. - Journal of Modern Information 36: 153159.

[35] Tamazian, A., Rao, B. B. (2010): Do economic, financial and institutional developments matter for environmental degradation? Evidence from transitional economies. - Energy Economics 32: 137-145.

[36] Wang, H. J., Chen, H. P., Liu, J. P. (2015): Arctic Sea ice decline intensified haze pollution in eastern China. - Atmospheric and Oceanic Science Letters 8(1):1-9.

[37] Xu, Y., Masui, T. (2009): Local air pollutant emission reduction and ancillary carbon benefits of $\mathrm{SO}_{2}$ control policies: application of AIM/CGE model to China. - European Journal of Operational Research 198(1): 315-325.

[38] Zhou, Q. (2011): The effects of China's regional economic growth on the environmental quality: based on the empirical study of eastern central and western Kuznets curve. Statistics \& Information Forum 26: 45-51. 